\title{
Ergonomic Work Analysis: A Case in Precast Industry from the Use of OWAS and RULA Methods
}

\author{
Éverton de Sousa Abreu and Hélio Cavalcanti Albuquerque Neto
}

\begin{abstract}
The precast industry having activities that require great physical effort of workers, given that an increasing growth in the use of these constructions in components. Thus, the sector must have continuous monitoring of their activities, in order to seek interventions that aim to ensure a healthy work environment. With the intention to offer a healthy environment for workers, this study adopted the Ergonomic Work Analysis (EWA) as ergonomic diagnostic method to evaluate the working conditions imposed on workers of a precast industry located in the city of Teresina-PI. Was used two checklists established in the literature (OWAS and RULA) for the analysis with a sample of the population of workers who come each production sector in order to identify the postures taken by employees during the performance of work activities and their consequent discomforts and risks of developing diseases related to work. From the analysis there were many postural constraints made by workers and various areas of discomfort in the body, as well as poor conditions related to physical/environmental, generating disease development risks related to work. Finally, some recommendations were made in order to neutralize the bad working conditions identified.
\end{abstract}

Index Terms-Ergonomic work analysis, OWAS, precast industry, RULA.

\section{INTRODUCTION}

The construction industry is rising in most developing countries, among which we can mention Brazil. In recent years the sector had steady growth, being one of the main foundations of the industrial development of the country [1]. Thus there was the adoption of different construction practices, linking the use of new technologies and materials [2] which provided the spread of precast concrete elements [3] on the speed of construction and the lowest aggregate cost [4].

Although precast are becoming common in construction sites [5], these are characterized by activities that require great physical effort of workers, which is likely to cause harm to health thereof. Given this perspective, the methods of ergonomic studies arise as a major factor in the industrial environment, given the benefits that an improvement and qualification program brings in workers' health [6]. Among such methods, was highlight the OWAS and RULA to be widespread in literature, providing an analytical view of work and allowing a series of recommendations for improvements. Therefore, this study aims to conduct an ergonomic analysis in a precast industry from OWAS and RULA methods.

Manuscript received May 10, 2015; revised October 15, 2015.

The authors are with the Department of Industrial Engineering in the Federal University of Piaui, Teresina-PI-Brazil (e-mail: evertonsousa@hotmail.com, helio@ufpi.edu.br).

\section{Methodology}

The precast industry, study target, is located in the city of Teresina-Brazil and was chosen because of its representation in the trade of the region. Data were collected during the period of October to December 2014, checking the major sectors showed ergonomic problem. It should be noted that the data collection instruments were used after knowledge on the part of the author and are applied in days of common work. In order to explain the instruments used, it can be list its main features below.

\section{A. OWAS}

The Ovako Working Posture Analysing System (OWAS) was developed in 1977 by researchers Karu, Kansi and Kuorinka, which is the observation and analysis of the different positions taken by the workers, by combining three codes: the first related to the position dorsal worker, the second with the position of the arms and the third with the position of the legs [7].

\section{B. RULA}

Rapid Upper Limb Assessment (RULA) was developed by Lynn McAtamney and Nigel Corlett, in 1993, for an analysis of body posture, focusing on upper body, but including the bottom [8] where efforts will be evaluated made by employees during the course of its activities that may lead to muscle fatigue and possible diseases of the upper limb work-related [9].

\section{RESUlts}

By knowing the entire process of producing precast, it was found that there are three sectors in a higher incidence of great physical effort movements: ironware, concreting and formwork/curing. The first sector consists of the construction of the metallic structure of precast, and blacksmiths are responsible for cutting and put the iron in your application site following the design specifications.

The second sector, the concreting, consist the machining of concrete to be used in the manufacture of precast parts, the workers being in charge of collecting, transporting and mixing the raw materials — sand, gravel and cement — to give the fresh concrete, and transport it to the next step. The third and last sector, the formwork/curing consists in forming the pre-molding being responsible for the masons to perform the addition, alignment and density of the concrete mass in the mold. Thus, through the activities developed by the workers and the working conditions at each stage of the production process, was begun the analysis. 


\section{A. Ironware Sector}

In iron cutting activity, the employee assumes an inclined dorsal posture, with both arms down and the two straight legs. Fig. 1 shows the movements of workers. Given the combination of the positions taken during the course of iron cutter and the cargo handled, the OWAS method considers that the physical burden of posture is slightly harmful, in this way some modifications are needed to change the posture in the near future. However, according to the RULA method it should perform an observation of activity, where changes may be required.

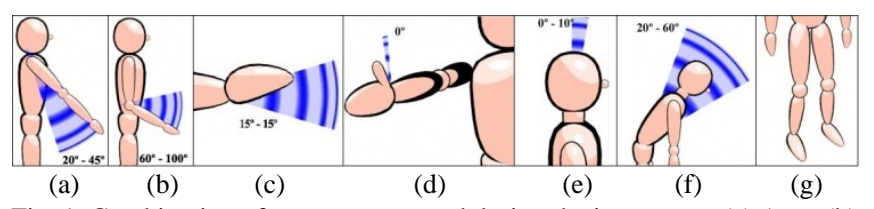

Fig. 1. Combination of postures assumed during the iron cutter: (a) Arm; (b) Forearm; (c) Handle; (d) Rotation of the handle; (e) The neck; (f) Stem; (g) Legs.

In the activity of assembling the metal structure, the worker assumes an inclined dorsal posture, with both arms down and the two straight legs. The cargo handled by the employee is between 10 and $20 \mathrm{~kg}$, in which Fig. 2 illustrates this activity. About the prospect of OWAS method, has a slightly harmful posture, where steps are needed to change the posture in the near future. Already through the RULA method, it appears that we should perform an observation of activity, where changes may be required.

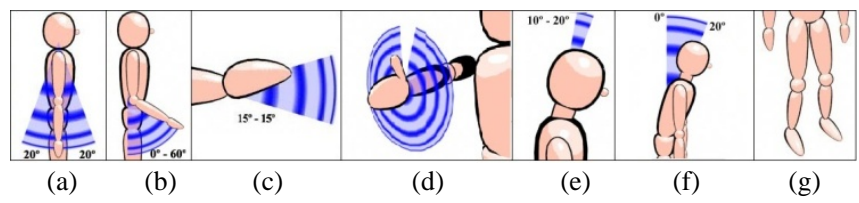

Fig. 2. Combination of postures adopted during the assembly of the metal structure (a) Arm; (b) Forearm; (c) Handle; (d) Rotation of the handle; (e) The neck; (f) Stem; (g) Legs.

\section{B. Concreting Sector}

At harvest activity of the raw material, where was use the shovel, the worker assumes an inclined dorsal posture, with both arms down and the two straight legs, as can be evidenced by Fig. 3. The cargo handled by the worker in this activity is less than $10 \mathrm{~kg}$ (each drawing with shovel). Thus, the method OWAS considered a slightly harmful posture, with the need to take action to change the position in the near future. The RULA method, in turn, finds that requires investigation and immediate changes to the workplace.

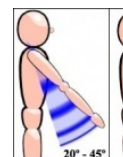

(a)

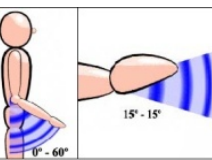

(b)

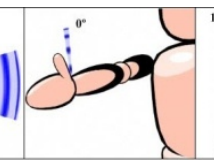

(d)

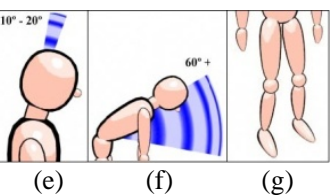

(e) (g)
Fig. 3. Combination of postures assumed during harvest activity of the raw material: (a) Arm; (b) Forearm; (c) Handle; (d) Rotation of the handle; (e) The neck; (f) Stem; (g) Legs.

With regard to the activity of pouring the raw materials to the mixer machine, there is a sloped back posture with both arms upwards and a straight leg cargo handled in excess of 20 kg, shown in Fig. 4. The OWAS method considers a normally harmful posture, where it is necessary to adopt measures to change the position as soon as possible. In line with this analysis, the method RULA states that requires investigation and immediate changes to the workplace.

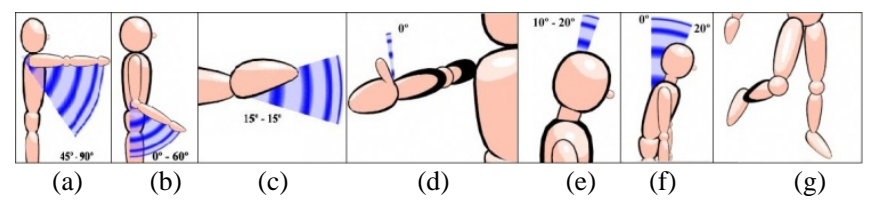

Fig. 4. Combination of positions taken during the activity to dump the raw material into the mixer: (a) Arm; (b) Forearm; (c) Handle; (d) Rotation of the handle; (e) The neck; (f) Stem; (g) Legs.

In the concrete transport activity to the formwork, the worker assumes a straight dorsal posture, with both arms down, with displacement with legs and a busy load of $20 \mathrm{~kg}$, according to Fig. 5. The method OWAS considers a normal posture, without requiring remedial measures. Furthermore, the method observes that RULA no need for research or changes introduced soon.

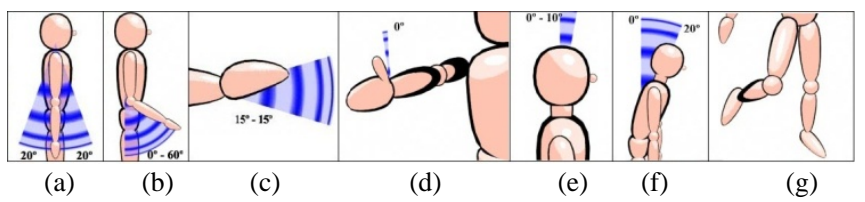

Fig. 5. Combination of positions taken during the actual transport: (a) Arm; (b) Forearm; (c) Handle; (d) Rotation of the handle; (e) The neck; (f) Stem; (g) Legs.

\section{Formwork/curing Sector}

When performing the activity of adding concrete in molds, the employee assumes an inclined dorsal posture, one arm up and the two straight legs, with the cargo handled by him less than $10 \mathrm{~kg}$, as shown in Fig. 6. The method OWAS considers a slightly harmful posture, with the need to take action to change the position in the near future. Already RULA method considers should be made a note of the activity, may be required some changes.

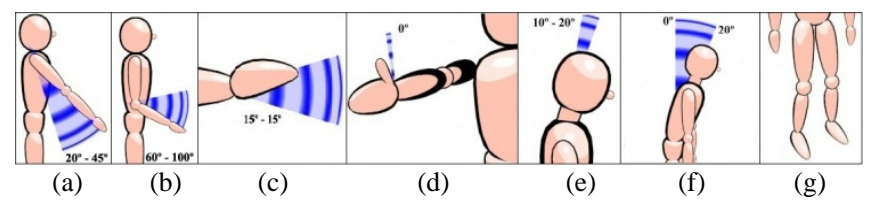

Fig. 6. Combination assumed postures to add concrete formwork in: (a) Arm; (b) Forearm; (c) Handle; (d) Rotation of the handle; (e) The neck; (f) Stem; (g) Legs.

As for the retouch activity of preformed parts, it was observed that the worker assumes an inclined dorsal posture and slightly twisted, with arms down and a straight leg, with the smallest busy load $10 \mathrm{~kg}$. Fig. 7 illustrates these various positions. The OWAS method indicates that there is a risk to workers' health, because it is considered adopting a slightly harmful posture, with the need to take action to change the position in the near future. The RULA method finds that requires an investigation into the process, and subsequent changes.

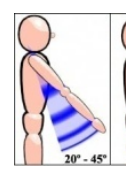

(a)

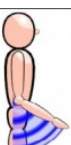

(b)

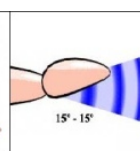

(c)

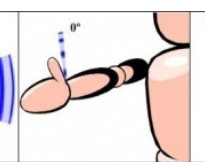

(d)

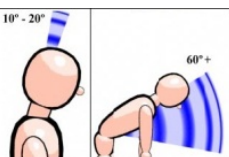

(e) (f) (g)
Fig. 7. Combination of postures assumed when performing the finishing retouches on the precast part: (a) Arm; (b) Forearm; (c) Handle; (d) Rotation of the handle; (e) The neck; (f) Stem; (g) Legs. 


\section{Analysis Of The Results}

Given the similarity in applications of OWAS and RULA methods, the comparison of results provides a better loyalty of possible intervention actions from them, since many are the postural constraints pointed out by them. Thus, comparing the results of the methods for each activity, obtaining the following analysis:

- For iron cutting and assembly activities of the metallic structure: the results obtained with the application of models were similar, where both models found that this activity requires investigation, whether or modifications may be required of the work station in the near future;

- For harvest activity of the raw material: although both results suggest the need for changes in jobs, there was a difference in the urgency of these, being which OWAS pointed in less emergency changes, while the RULA pointed out the need for immediate changes;

- For the activity to dump the raw material into the mixer: the two methods obtained similar results, where both applications indicated the urgent need for changes in jobs and working postures;

- For concrete transport activity: yielded different results between the two methods, where the OWAS did not consider the requirement of corrective measures, while the RULA indicated the need for research and changes soon;

- For the activity of adding concrete in molds: Similar results showed that both models have identified that this activity requires investigations, whether or modifications may be required of the job in the near future;

- For retouch activity in the pre-molded parts: the results obtained from the application of the methods were equivalent, where both demonstrated the need for investigations and modifications soon the jobs and working postures.

Before the comparison, one can see that despite some differences. Approximately $93 \%$ of the results indicated the need for corrective actions with regard to posture and jobs. Thus, it is understood that, despite the similarity analysis of OWAS and RULA methods, the applicability of the latter is more detailed compared to the first, considering that in his analysis are considered more variables.

\section{CONCLUSION}

Currently, the working condition provided by the companies has received great attention when it comes to reactions that inappropriate work conditions can bring to the workers. In this way, the search for the adequacy of the work to the individual is increasingly common, considering that provides a healthy environment, creating thus a better quality of life and improved worker productivity.

In this sense, the present study aimed to analyze the ergonomically activities performed by workers of the production department of a precast industry, based on the use of posture analysis techniques of OWAS and RULA methods. In general, the results of both the applied instruments linked to the lack of ergonomic training and labor gymnastics, and physical/environmental factors such as exposure to sunlight, high temperature and high levels of noise, lead to worker a considerable number of fatigue and discomfort, especially in the dorsal and lumbar regions, hands and arms and legs, in view of the exposure time to work. Thus, before the various postural constraints raised by the methods used above, emerges the need to identify some recommendations to improve operating conditions in the jobs studied, such as:

- For iron cutting activity: it is suggested that an adjustment must be made at the time of cutting bed according to the height of the workers, thereby to improve posture while occurs the activity by decreasing the stress load on the neck and spine. In addition, a study of the automation activity, the use of an automatic cutting machine in which the official position itself only iron for cutting is predictable, can be high;

- For the activity of assembly of the metal structure: can be suggested adjustments to the height of the mounting bench according to the height of the workers, preventing buckling during this operation constantly, and targeting labor gymnastics to hands and fingers, since they are the body parts most commonly used in this activity;

- For harvest activity of the raw material: to be directed dedicated staff to perform these activities, was recommended the rotation of these with the other employees in the sector, with a view postural conditions in their achievements as well as work breaks around 10 minutes every hour worked, seeking to avoid monotony and repetitiveness, and the resulting discomfort arising from these activities;

- For concrete transport activity: we recommend a floor cleaning where they circulate employees with hand carts, allowing thus to flow with greater ease, reducing the exercise of the legs and arms effort to move the carts;

- For performing the activity of adding concrete in molds: suggest the height adjustment of the benches of formwork, according to the stature of the workers, in order to avoid the column inclination to perform this activity, in addition to not need to raise the arm above 45 degrees relative to the line of the body;

- For the retouch activity of preformed parts: one adjustment at the time of the stands where the demolded parts are arranged is suggested, according to the height of the worker, so that there is not the steep slope and bending the spine to perform this activity;

- It is suggested also the adequate and continuous use of Personal Protective Equipment (PPE) during the execution of activities, avoiding mental fatigue generated by the noises emitted in working machines.

It is noteworthy that the latter two recommendations, although no ergonomic appeal, are inwardly of the adequacy of the workplace to the worker, goal of ergonomics. However, all recommendations suggested activities contributing to the reduction or neutralization of fatigue and work-related diseases.

\section{REFERENCES}

[1] W. T. Sarcinelli, “Construção enxuta através da padronização de tarefas e projetos (Lean construction by standardizing tasks and projects)," Monografia (Especialização) em Construção Civil (Monograph (Specialisation) in Construction), Univ. Fed. de Minas Gerais, Vitória, 2008.

[2] A. S. Prestes, F. P. Silva, and J. A. Krüger, “Avaliação ergonômica do transporte e manuseio de fôrmas de alumínio utilizadas para moldagem de paredes de concreto na construção civil (Ergonomic transport assessment and handling of aluminum molds used for molding 
concrete walls in civil construction)," Publ. UEPG Exact Earth Sci., Agr. Sci. Eng., vol. 15, pp. 129-138, Ago. 2009.

[3] S. M. B. Serra, M. de A. Ferreira, and B. N. Pigozzo, "Evolução dos pré-fabricados de concreto (Evolution of the prefabricated concrete)," presented at the First Encontro Nacional de Pesquisa Projeto Produção em Concreto Pré-moldado (presented at the First National Meeting of Production Research Project in Precast Concrete), São Carlos, São Paulo, November 03-04, 2005.

[4] L. Rose, "Risk management project for work with precast concrete shells," Journal of Prevention, Assessment and Rehabilitation, vol. 41, no. 1, 2012.

[5] P. E. F. de Campos. (2006). Sem restrições tecnológicas os pré-fabricados precisam romper obstáculos culturais. Associaçãa Brasileira da Construção Industrializada de Concreto. [Online]. Available: http://www.abcic.org.br/artigo2.asp

[6] F. A. Pinheiro, B. T. Tróccoli, and C. V. Carvalho, "Validação do Questionário Nórdico de Sintomas Osteomusculares como medida de morbidade (Validation of the Nordic Musculoskeletal Questionnaire as morbidity measure)," Revista de Saúde Pública (Public Health Magazine), vol. 36, no. 3, pp. 307-312, 2002.

[7] H. S. Ketan and A. K. Al-Zuheri, "Correcting working postures in water pump assembly tasks using the OVAKO work analysis system (OWAS)," Al-Khwarizmi Engineering Journal, vol. 4, no. 3, pp. 8-17, Sep. 2008.

[8] S. Dockrell, S. E. O’Grady, K. Bennett, C. Mullarkey, R. Connell, R. Ruddy, S. Twomey, and C. Flannery, "An investigation of the reliability of rapid upper limb assessment (RULA) as a method of assessment of children's computing posture," Applied Ergonomics, vol. 43, no. 3, May 2012.

[9] F. Serranheira and A. S. Uva, "LER/DORT: Que métodos de avaliação do risco? (WRMDs: That methods of evaluating risk?)," Revista Brasileira de Saúde Ocupacional (Occupational Health Magazine), São Paulo, vol. 35, no. 122, p. 314-326, 2010.

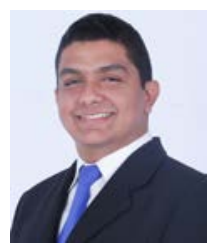

E. de S. Abreu, graduate in production engineering from the Federal University of Piauí, Brazil, in 2014.

$\mathrm{He}$ is a postgraduate student in Occupational Safety Engineering, from the Graduate Center and Parnaíba Valley Extension, Brazil, in 2015.

He works with ergonomic and occupational health issues in industrial environments. Previously he worked in the quality sector in the precast industry in performing quality tests in pre and post-production of precast parts.

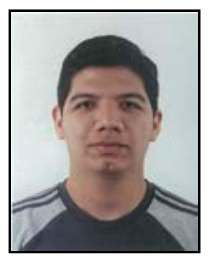

Hélio Cavalcanti Albuquerque Neto was born in Campina Grande, Brazil on August 23, 1985. He finished his under graduation in 2010, which majored in industrial engineering at Federal University of Campina Grande, located in Campina Grande.

$\mathrm{He}$ is a professor at Industrial Engineering Department in Federal University of Piauí, having experience in Quality, Sustainability and Health and Safety.

Prof. Albuquerque Neto is an editorial member of American Journal of Health Research and student of the doctoral program in Occupational Safety and Health, University of Porto, a researcher of the Group on Agro-industrial Processes and Products of Savannah and a member of the Research Laboratory of Applied Engineering and Production Economics, acting on the following subjects: thermal environment, safety in construction industry and corporate sustainability. 